\title{
Arbor
}

\section{España y el español en Taiwán*}

\author{
Mauh-Tsun Chang
}

Arbor CLXXIX, 705 (Septiembre 2004), 173-191 pp.

\section{Introducción}

\section{Reseña histórica de España en taiwán}

Hoy día la popularidad de español en Taiwán ${ }^{1}$, como en cualquier otra sociedad internacional es un hecho, pero también es otro hecho, que algunos de los habitantes de Taiwan en el siglo XVII hablaron español durante algún tiempo. Para explicar esto vamos a hablar un poco de la historia de España, un país en el que -en los siglos XVI y XVII- «nunca se ponía el sol».

La reina Isabel I de Castilla se casó con Fernando el heredero del Reino de Aragón en el año 1479, y en breve tuvo lugar la integración de ambos territorios, de manera el nuevo país se convirtió en un estado importante. En 1492, expulsaron a los moros que quedaban al sur de la Península Ibérica, con lo cual la unidad territorial fue mayor; el mismo año, Cristóbal Colón descubrió las islas del Caribe y durante los siglos XVI y XVII España empezó a colonizar el continente americano. En el año 1543, se utilizó el nombre de Felipe II para denominar a las Filipinas, y desde poco después este archipiélago se convirtió en nueva tierra colonial de España, de ahí que de España se dijera que era «el país en donde nunca se ponía el sol». Esta situación duró hasta la Guerra de Hispanoamericana del año 1898, en que España perdió las Filipinas y Guam $^{2}$. Así fue como tuvo lugar el final del final del imperio español.

En el siglo XVII, el intercambio comercial entre Fujian y Manila era estable, pero en el año 1624 los holandeses tomaron el puerto de An-Pin,

* El autor agradece el respaldo financiero brindado por el Consejo Nacional de Ciencias, de la República de China en Taiwán a través del proyecto NSC91-2411-H-032-011, NSC 92-2411-H-032-005 y NSC 93-2411-H-032-016. 
para cortar este comercio. Por eso los españoles pusieron una fuerza militar al norte de Taiwan, en Keelung, para así defender la ruta comercial. Allí los españoles estuvieron durante 16 años (1626-1642): y se relacionaron los aborígenes de los pueblos más cercanos, de manera que, según las fuentes históricas, «los chiquillos hablaban muy bien el español, incluso sabían repetir con propiedad las sucias palabras de los soldados $\varkappa^{3}$. Además los misioneros aprovecharon este punto para ir a China Continental, ya que no podían ir desde Macau pues no se lo permitían los portugueses. También durante los años 1629 a 1637, los españoles construyeron el fuerte de Santo Domingo, en Tanshui. Ésta sólo fue una pequeña fortaleza militar de madera.

Después, los holandeses empezaron a expandirse hacia el norte de Taiwan. Y en el año 1642 expulsaron a los españoles. Al año siguiente, los holandeses utilizaron ladrillos, piedras y cal para reconstruir el antiguo castillo de Santo Domingo. Como los chinos llamaban a los holandeses «Houng-Mao», es decir, personas de pelo rojo, así este edificio se acabó denominando «el edificio de los Houng-Mao». Hoy la gente llama a este monumento Castillo de Santo Domingo o Castillo de Houng-Mao. Ahora este lugar es uno de los lugares turísticos más importantes de Taiwán.

Como España estuvo poco tiempo en Taiwán, y además sólo en un par de lugares, no se puede decir que gobernara la isla. Sin embargo, si se puede decir esto de los holandeses, que estuvieron desde 1624 a 1662, y luego, en el norte, desde 1664 a 1668. Además los holandeses utilizaron Taiwán como una base intermedia de su comercio intra-asiático, con lo que lograron la expansión de su poder y beneficio.

Podemos acabar diciendo que el nombre portugués de Ilha Formosa, al que los españoles llamaban Isla Hermosa, fue popularizado después por los mapas holandeses y franceses, y con este nombre Taiwán ha sido conocido durante muchos años en Europa y en el Mundo occidental.

Tras este breve enfoque histórico, el lector se daría mejor cuenta de la causa de la existencia de tan abundante términos hispanizantes en Taiwán. A continuación, vamos a analizar desde el punto de la vista de la cultura del consumo y el aprendizaje de español para comentar el papel de Taiwán en el escenario internacional y el intercambio entre Taiwán y España, en los años recientes:

La posición geográfica de Taiwán se halla en el Pacífico asiático, entre China Continental y el Japón. Desde el pasado Taiwán ya se encontraba en una zona multicultural, pues la situación geográfica estratégica de Taiwán hizo que ella siempre fuese la presa de las potencias militares; ahora no sólo China Continental tiene interés por reunificarla, sino que Japón 
aún se acuerda de sus pasos por Taiwán ya que la misma había sido su colonia por cincuenta años. Retrospectivamente en la historia hasta podemos remontar a las potencias europeas, ya que tanto Holanda como España también habían dejado sus rastros en Taiwán. Consecuentemente, las diferentes culturas referidas influyeron profundamente a Taiwán.

En los años recientes, el gobierno de Taiwán ha propuesto una política de localización, pero la misma no equivale ni a un autoenclaustramiento por sí mismo, ni a la negación del intercambio con las culturas extranjeras, sino a reflexionar la naturaleza propia mediante el estímulo exterior, y así promover una transformación impresionante de la cultura autóctona taiwanesa. Debido a que la eficacia de la localización continúa su ascenso, la tendencia del consumo de Taiwán vuelve a su originalidad, ya que al enfatizar su localización, el carácter de la misma naturaleza del producto se eleva, y así las culturas locales y extranjeras se distinguen y hasta se embellecen notoriamente entre sí.

La compleja situación política de Taiwán hace que las intervenciones externas pesan mucho sobre su diplomacia, porque Taiwán se afana por obtener el reconocimiento de la comunidad internacional, y por ende tiene que trabajar más en el sector del comercio y el arte, libre de la política y a través de buenas representaciones multi-sectoriales para elevar el status internacional de Taiwan; Así no solamente se consigue desarrollar la fuerza original de Taiwán, sino que le permite converger rápidamente con los valores positivos de la cultura extranjera. Gracias a la influencia de su nacionalismo de apertura, Taiwán acoge beneplácidamente a las culturas extranjeras. Más los orientales son hábiles por convertir las circunstancias desfavorables en favorables, de sacar buenas partidas de los juegos adversos, la interacción entre las culturas locales y extranjeras desde hace mucho tiempo, han consolidado los lazos existentes entre las extranjera y la taiwanesa.

La cultura popular de Taiwán recibe hoy día gran influencia de las japonesa y coreana, las razones principales son la cercanía geográfica, la similitud étnica y el factor común de constituirse en países orientales que comparten el confucionismo.

Pero la cultura hispánica también influyó en mayor grado a Taiwán; además de que trescientos años atrás los españoles ya habían visitado a la Isla Formosa y habían dejado numerosas construcciones y nombres en la región norteña de Taiwán, tal como el fuerte de Santo Domingo ${ }^{5}$, así deja una marca indeleble en la historia de Taiwán. Como Taiwán desde hace tiempo que viene recibiendo presión política, por lo tanto, está ansiosa por ostentar un status internacional. Bajo tales circunstancias, La 
sociedad taiwanesa se ha abierto para converger con las culturas europea y norteamericana, el gobierno taiwanés también habilitó la importación masiva de manos de obra filipinas, y hasta está considerando adoptar al inglés como la segunda lengua oficial.

La música no tiene frontera por ser una lengua universal, y en especial la latina que ha conquistado al mundo. Cantantes como Ricky Martín, Julio Iglesias y Shakira son archiconocidos por sus canciones. Las canciones en español siempre expresan un ritmo rico entre los estilos gitano y árabe, mientras que la samba brasileña agrega un toque de claridad y rápidez, Por su parte, la música cubana está impregnada del estilo de Jazz. Éstas músicas, como una representación de la cultura latina, se caracteriza por un ritmo contagiante acompañada de emocionantes letras, de manera que a la gente le encanta escucharla una y otras veces, así va recibiendo la cultura latina y conociendo un poco más a los países hispanoparlantes.

En Taiwán, las marcas de vestido usan mucho las lenguas extranjeras, ya que el uso de las lenguas extranjeras puede crear una sensación espacial de estar en el extranjero. Simultáneamente combinadas con la atractiva moda se consigue una sensación ficticia y así se trascienden las fronteras espacial y temporal. Especialmente cuando hoy día las modas se suceden vertiginosamente. Por su puesto la buena calidad de los productos es lo más importante. El saber adoptar adecuadamente las diferentes cualidades de las lenguas extranjeras es en sí un arte de mercadotecnia. En Taiwán, se adopta generalmente el francés cuando se desea transmitir el romanticis mo; el alemán cuando se desea expresar lo pragmático; el japonés cuando se desea congeniar con la juventud de la pubertad; y se recurre al español cuando se desea incitar el sentimiento de pasión, rico en color y calor. Por eso naturalmente los diseñadores de los países hispanoparlantes tienden a un diseño vestimental más atrevido y colorido. Estos atributos combinados con la buena calidad, con los diseños tradicionales muchas veces autóctonos, y con las marcas españolas, producen gran persuasión.

Es importante destacar aquí un factor sociolingüístico. Existe pues en Taiwán una gran población de trabajadores filipinos que se desempeñan principalmente como criadas y niñeras de hogar. Siendo las Filipinas una ex-colonia española, es naturalmente que los filipinos compartan la cultura hispánica con las familias taiwanesas y por ende con la sociedad taiwanesa. Entonces, esta popularidad hace que sea mejor que se adopte el español como marcas ya que tiene una relación más profunda y estrecha con Taiwán, tanto en la historia como en la modernidad. Este factor es muy influeyente pues el mercado asiático es muy diferente con el occidental, porque tuvo un pasado más cerrado y conservador, y ha sido más 
reservado en expresar los sentimientos. Otro factor igualmente importante constituye el contenido emocional del español, el que siendo una lengua multi-cultural y hasta multi-racial contiene un alto grado de aceptación. Así, comparativamente la lengua española adquiere una gran ventaja competitiva en Taiwán respecto a otras lenguas extranjeras.

El diseño atrevido de los colores es notorio en las modas de vestimentas, tal como sucede en las confecciones MANGO. Otro caso que sique fielmente esta regla lo constituye la serie «Siete Cinco Cinco» de los pantalones vaqueros de Blue Way.

Al pensar en España, relacionamos generalmente con la tauromaquía muy famosa por todo el mundo, por supuesto, la producción del cuero de España tiene una gran cantidad, así que España ha sido el país que exporta los productos del cuero. El cuero de Loewe es muy famoso por todo el mundo, y también tiene sus entusiastas en Taiwán; los zapatos de Camper que tienen la comodidad y creación, también son muy queridos por los consumidores del buen gusto. Estas dos famosas marcas españolas, aunque no llevan términos hispanizantes, lo mismo son muy conocidas por la gente de Taiwán, ya que en los últimos años, tanto la pasión como el estilo latino están de moda, y más todavía tras los Juegos Olímpicos.

Durante los Juegos Olímpicos del año 1992, España ha maravillado a todo el mundo con la hermosura de su ciudad de Barcelona, hasta hace poco se recordaba en Taiwán lo lindo de dicho evento, durante la inauguración de la venta en el mercado local de los vestidos de CUSTOBARCELONA. En dicha ocasión se insistió sobre su representación de lo humano y artístico de Barcelona.

España tiene muchos artistas de estándar mundial (citando a algunos: Pablo Picasso, Salvador Dalí, Joan Miró). Una compañía taiwanesa de construcción ha demonimado con el nombre del sobresaliente constructor Gaudí a toda una comunidad, cuyos edificios se asemejan al estilo del Palacio Güell de Gaudí.

El estilo español, además de ser notorio en los edificios, también se evidencia en las muñecas de cerámica $\mathbf{L L A D R O}^{6}$. Las muñecas de $\boldsymbol{L L A}$ $\boldsymbol{D R O}$ tienen la cara característica en forma de gota de agua y es especialmente famoso por su serie de personajes. En dichas cerámicas, los rostros humanos son tan reales y se llenan de imaginación como si fueran vivos, ni que decir de la maravillosa finura en mano. Lladró produce anualmente una serie de productos de cantidad limitada, y son siempre adquiridos por los entusiastas coleccionistas. 
El poder influyente del español llega hasta la industria local. Cuando mecionamos en Taiwán algo sobre España, las ideas que surgen generalmente en la mente de la gente son el flamenco y la tauromaquía, además de una melodía combinada con con el ritmo alegre de la guitarra. $\mathrm{O}$ sea, imágenes de una cultura llena del color y calor hispánico. Cuando una compañía desea denominar con términos extranjeros a su producto, tiene que considerar además de dichos términos, la cultura que lo representa. La lengua y cultura española es muy eficaz porque además de ser rica y colorida, tiene una pronunciación que no es tan dificil como algunas otras lenguas extranjeras. Entonces no es problema adoptar términos del español como marcas comerciales. Para mayor facilidad de recordarlas, muchas publicidades utilizan un ambiente extranjero a fin de crear un escenario atractivo para atraer a los consumidores de una manera natural y espontánea. Un buen ejemplo es el de la empresa BenQ, muy afamada en productos de la informática y ofimática, incluyendo la telefonía móvil. La filosofía de $\boldsymbol{B e n} \boldsymbol{Q}$ se basa en una concepción de disfrutar en el mundo, insistiendo en que el placer está en nuestro alrededor. En una serie de la publicidad televisiva de su teléfono móvil, se exhibe a una mujer esperando autobús en la parada, y de repente suena su móvil con una melodía típica del flamenco, entonces ella como si fuera hipnotizada comienza a bailar al son de las castañuelas. Rato después, ella se da cuenta que está todavía esperando al autobús, entonces coge el teléfono, y contesta en español "Perdona. ¡Hola! ¿Paco?». Esa forma de viva presentación no se conseguiría con otras lenguas extranjeras, salvo con el español. Es increíble la eficacia de persuasión de la cultura y lengua española, más que ninguna otra. De manera similar, encontramos otras publicidades televisivas presentando a las cortinas y mueblerías procedentes de España, y ponen de evidencia la tendencia creciente de la difusión de la cultura y el uso de la lengua de Cervantes.

\section{Presencia del español en Taiwán}

En Taiwán se contemplan muchas marcas comerciales cuyas denominaciones son vocablos extraídos del español, o del italiano o inglés (pero que por su origen común en el latín, son equivalentes en español). Así tenemos, por ejemplo, que NOVA y AURORA corresponden a dos famosos centros de compras (especializados en productos ofimáticos); que dos ca-

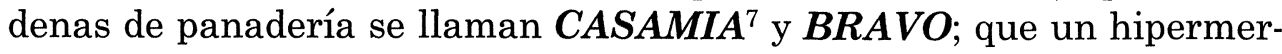
cado se llama $H O L A$; que una cadena de servicentro y hasta un canal te- 
levisivo coinciden en llevar la denominación FORMOSA; que un telediario se denomina $\boldsymbol{E R A}$; que una famosa revista turística se llama $B L A N$ $\boldsymbol{C A}$; que un alimento enlatado para perros tiene la marca $\boldsymbol{C E S A R ;}$ que la gastronomía está representada por la famosa cadena de pizzería como el caso de DOMINO; de chocolates como el caso de CHOCOS; como el caso del ácido láctico BIFIDO; mientras que en marcas de coche son numerosísimas como PRIMERA, CEFIRO, TIERRA, SOLIO, etc., y mucha gente se va a probar el buen café de $\boldsymbol{D A N T E}$ que vale treinta y cinco dólares (moneda taiwanesa): aproximadamente un euro. El popular café Dante útiliza el nombre del poeta italiano Dante, que también se escribe así en español. Las marcas aparecidas en las calles son numerosas. Algunas de ellas se toman del inglés, otras del español, y otras sólo tienen un significado único.

Hemos indicado en nuestro artículo "Aprender español con placer: desde el punto de vista de la publicidad comercial», que cuando una empresa denomina a su marca suele adoptar primeramente la transliteración, como insiste Wang (2002): «para conseguir un nombre éxitoso de la compañía, el mismo tiene que ser breve y fácil de recordar». Esta idea coincide con la de Bassat quien señala a la función del eslogan de la siguiente manera: "Corto y memorable; profundo y brillante; simple y único; impactante, perdurable, creíble y relevante» (1993). Así, las empresas emplean los diseñadores profesionales de arte y marketing para que, según el carácter de los productos, adopten la forma de transliteración, dependiendo de la pronunciación de la marca y de la calidad del producto para así ofrecer la traducción llamativa de una marca ${ }^{8}$. Por ejemplo: IMPREZA de Subaru, METROSTAR ${ }^{9}$ (Es ella) de Ford.

Antaño, Taiwán era más bien una sociedad cerrada y conservadora. Empero, con el fenómeno de la globalización, la sociedad taiwanesa hoy se dirige hacia la internacionalización. Por eso pueden verse claramente los diversos letreros por la calle, incluyendo los productos europeos y americanos. Generalmente, las marcas populares son la primera selección del público, y, a la inversa, influyen en la gente, pues todo el mundo conoce las principales marcas famosas, hasta las puede decir sin olvidarlas; y aún más, las marcas se convierten en una parte de nuestra vida diaria. Sin tomar conciencia de ese fenómeno, la gente y las marcas famosas ya forman parte de nuestra cultura popular y así lo recordamos. Si logramos canalizar la atención de los alumnos del español hacia tales marcas en nuestras clases, es muy posible que elevemos el interés y la capacidad de los alumnos para aprender el español. 
Para un mejor desarrollo sistemático del tema, hemos clasificado los términos comerciales hispanizantes encontrados en Taiwán, en un total de seis secciones, según su relación con las diversas actividades cotidianas, que son: Gastronomía, Vestimenta, Vivienda, Transporte, Educación y Entretenimiento. A fin de facilitar una mejor comprensión al lector hispanoparlantes, también hemos incluído una reseña histórica acerca de la influencia española en Taiwán.

\section{La gastronomía}

El tema del presente artículo es «aprender el español con placer». Por consiguiente, dependemos principalmente de los productos cuyas marcas tienen algún significado en español, o sea términos hispanizantes. Por ejemplo: una cadena de restaurantes en Taipei ha utilizado la homofonía del vocablo $\boldsymbol{M A L A}$ para describir a su plato principal que es un «shabu shabu» superpicante. Tan picante es ese plato que a la vez lo hace muy sabroso, que hasta produce en quien lo come una extraña sensación que entremezcla el amor con el odio. Amor por su delicia, y odio por el extremo picante insoportable. Y el chocolate $C H O C O S$ (un calamarito): son excelentes ejemplos de la transliteración. Si pudieramos adoptarlos con ellos motivaríamos a nuestros estudiantes, y podríamos convertir al aprendizaje del español en algo placentero. Las siguientes marcas son ampliamente conocidas en el mercado taiwanés, y las vamos a analizar conforme a su significado en español:

Para una mejor comprensión hemos subclasificado a esta sección de gastromonía en un total de 5 grupos:

a. Cafetería. Tras nuestra búsqueda hemos encontrado y verificado las siguientes marcas que llevan términos españoles o extraídos del español, a saber:

DANTE, GUSTO, MAYA, MODO, OSO CAFE, CAFE DE ROMA, PRIMO CAFE, TU CAFE, TINA.

b. Golosinas. En esta sección hemos hallado a las siguientes que llevan términos españoles o extraídos del español, a saber:

CHOCOS (calamaritos): CHUPA CHUPS, EXTRA (goma de masticar): $M A R I N A$ (soja tostada): MILANO (galletas): OREO (galletas): ORION (chocolate): PATATA, KINDER BUENO, PEZ (caramelos): POCA (patatas): VIVA (pistachos): SERENA (rollo de huevo).

c. Vinos y tabacos. Aquí hemos hallado a las siguientes que llevan términos españoles o extraídos del español, a saber: 
- CORONA (cerveza): CUBA LIBRE, HABANO (puro): MARQUES DE PUERTO, SAN MIGUEL (cerveza) y los vinos SIGLO, TORRE, SANTA HELENA, SANTA RITA.

d. Restaurante. La verdad es que hay demasiados restaurantes y dentro de nuestra posibilidad hemos hallado los siguientes que llevan términos españoles o extraídos del español, a saber:

AYA, BOLERO, CELESTIAL, COCA, DITA, FLOR, DON QUIXOTE, IR CHINA, MALA, PONDEROSA, PRONTO, SABRINA, SARA, SOSO, TAPAS BAR, TOROS, VINO VINO.

e. Panadería y pastelería. Son menos que los restaurantes e individualizamos los siguientes que llevan términos españoles o extraídos del español, a saber:

AMO, BRAVO, CASAMIA, IRIS, ROSA.

\section{La vestimenta (incluyendo artículos de primera necesidad)}

La vestimenta otorga además de protección, elegancia y placer, tanto para el hombre como para la mujer. En comparación con nuestros ancestros, la gente moderna busca valor añadido a su vestimenta. Por ende, los taiwaneses gastan mucho dinero en comprar los vestidos, más aún cuando el mercado taiwanés se dirige hacia la internacionalización, haciendo que las marcas extranjeras sean altamente aceptadas. Y aunque el lector no lo sabe o percibe, existen numerosos vocablos españoles entre tales marcas. Así tenemos el bañador $\boldsymbol{A R E N A}$, el cosmético de origen coreano que lleva el nombre COREANA, la perfumería $\boldsymbol{M A S A}$, etc.

Tras nuestra búsqueda hemos encontrado y verificado a las siguientes que llevan términos españoles o extraídos del español, a saber:

a. Artículos de uso diario: Los siguientes que llevan términos españoles o extraídos del español, a saber: $\boldsymbol{A N D A N T E}$ (papel higiénico): $\boldsymbol{B L A N C A}$ (análisis del estado de embarazo): $\boldsymbol{R A T A}$ (insecticida): SEPIA (champú): TICO (polvo dentífrico): BARBARA (ropa interior): REINA (panty).

b. Relojería. Encontramos las siguientes que son términos españoles, o que encuentran significado en español, a saber: BELUGA, OMEGA y SECTOR.

c. Calzados. Encontramos las siguientes: DIANA, DIVA, ELENA y ESPERANZA.

d. Vestimenta. Encontramos las siguientes: ARENA (bañador): BONITA (bolsa): CIEN (vaquero): CUSTO BARCELONA, DITA, 
ELISA (joyería): EMA, FELINO, FILA, FRANCO, GALA, GOYA, HATO, IRIS, MANGO, NÁUTICA, OSCAR, OSCURO, POLO, POMA, PRESTO, PROMINENTE, PUMA , RITA, SARA, SIETE CINCO CINCO (vaquero): SODA, SOFÍA (joyería): $\boldsymbol{Z A R A}$.

e. Cosméticos. Encontramos a las siguientes: CASANOVA, COREANA, FERIA, HITO, HUGO, LA VENUS, LÚCIDO, MASA, MODA, NEBLINA, PUPA, UNO,

f. Peluquería. Encontramos a las siguientes: DOS, EROS 4, MENTOR.

\section{La vivienda}

Primero, hay un proverbio chino archiconocido que dice «el orden se da primero en la casa, y luego se extiende al país, y de allí al mundo entero». La casa es el lugar de resguardo y también nuestro hogar tanto para el descanso del cuerpo como del espíritu. La gente hoy en día sufre de mucho estrés, lo que ha hecho que en los últimos años, el ocio se haya convertido en una moda popular, por lo tanto, las viviendas europeas también cobraron buena fama. Muchos edificios de Taiwán llevan denominaciones del español y son muy bien acogidos por los consumidores.

Existen también negocios cuya denominación guarda relación con el español. Tenemos que el saludo $\boldsymbol{H O L A}$ en el español como nombre de una famosa tienda de decoración hogareña, granjea mucha simpatía. Por coincidencia, algunos hoteles locales llevan palabras del español, tal como el Hotel FORTUNA, el GALA, el GLORIA, el CAPITAL TAIPEI, etc. La mayoría de estas denominaciones hoteleras devienen de una traducción libre, sólo encontramos un caso de homofonía que es el Hotel SANTOS. Seguidamente ofrecemos la subclasificación que hemos realizado con las siguientes marcas que llevan términos españoles o extraídos del español, a saber:

Los comercios que guardan relaciona con el hogar son : empresa de la mudanza @MIGO, hipermercado especializado en los artículos del hogar HOLA, empresa de cablevisión CASA, empresa constructora MODER$N A$, tienda de edredones PICO, línea de electrodomésticos PROTON, la insecticida $R A T A$, piso de cerámica $R O M A$, inmobiliaria $S A N$ JOSE, polvo dentífrico TICO, bañera TINA, tienda de equipos de sonido VICTOR, camas VICTORIA. 


\section{El Transporte}

Antaño, los medios de transporte nos proporcionaban generalmente una lentitud que hoy no lo podemos casi ni imaginar, mientras que hoy casi todo el mundo anda en coche, ya que impera la noción de que el tiempo es dinero. Muchas compañías de coches se concentran en la actividad del sol que representa España, así que eligen el español para denominar a los coches de su empresa, al mismo tiempo provoca una tendencia de la denominación de coche en lenguas extranjeras. Las palabras comerciales al igual que el español tales como: el bus de CAPITAL, la compañía de coche de FORMOSA, el banco METRO (de Filipinas) y el transporte METRO, el servicio de entrega rápida adopta como marca a @migo, el papel higiénico del brisa primaveral de ANDANTE. Según nuestra investigación, en la sección del tráfico, las publicidades de coches ocupan una gran parte, por lo cual, esta sección se divide en dos partes:

\subsection{Partes, accesorios y repuestos para automóviles: petróleos ARECA, FORMOSA $y$ TOTAL; cubiertas CONTINENTAL, FE- DERAL $y$ SONAR; lubricantes FINA; lavacoches PINGO; faros para coche TURBO}

\subsection{El nombre de las marcas de coches $y$ motores $^{10}$ :}

Las marcas que suelen verse en nuestro país tales como, el coche de PRIMERA, CEFIRO, TIERRA, SOLIO, etc. La forma externa de esas marcas tienen una imagen inglesa, pero en realidad no son palabras inglesas, sino españolas.

Tomamos el caso del coche «Santa Fe» de Hyundai, cuyo nombre corresponde al mismo tiempo al nombre de una ciudad que hemos encontrado en los siguientes países: Argentina, Chile, Cuba y Los Estado Unidos. De esta manera, la empresa surcoreana parece sugerir una omnipresencia de su coche Santa Fe, al igual que la ciudad del mismo nombre que se encuentra por todos los rincones del mundo! En el caso de España, encontramos al famoso coche «SEAT», que para destacar su procedencia española, ha denominado a la mayoría de su serie con el nombre de las ciudades españolas, por ejemplo: Alhambra, Cordoba, Ibiza, León y Toledo. Todos estos cinco nombres corresponden a ciudades de España. A su vez, resulta muy interesante el caso del coche "Cadillac» de EE.UU. que lleva la denominación «Toledo», ya que ésa había sido la ca- 
pital del Imperio español en el siglo XIX. En la actualidad es el modelo más popular del grupo de GM, el cual presenta una apariencia aerodinámica, muy diferente al tradicional estilo conservador y cuadrangular, con un estilo muy europeo, hasta se puede decir que representa una innovación en el diseño de Cadillac, que apartir del modelo Seville, ha incre mentado su preferencia por el diseño europeo.

Seguidamente se ofrece un listado de las marcas de automóviles que se han podido encontrar en el mercado de Taiwán, exceptuando a las que ya no están en venta ni a las que están por lanzarse al mercado. El orden seguido es el del abecedario:

CITROËN: X-SARA.

CHEVROLET: CAMERO.

CHRYSLER: NEXT NEON.

DAIHATSU: MIRA, SOCIAL.

DODGE: NEON.

FIAT: PUNTO.

FORD: ACTIVA, CARNAVAL, FESTIVA, FIESTA, LÁSER, MERCURY SABLE, METROSTAR, PREMIO, PRONTO, SIERRA, TIERRA, VISTA, VIVID.

FORMOSA: MATIZ.

GENERAL MOTORS: SAFARI.

Holden: ASTRA, FRONTERA.

HONDA: del SOL, JAZZ, RODEO.

HYUNDAI: PRECISION, SANTA FE, SONATA.

ISUZU: RODEO.

KIA: $\boldsymbol{R I O}$.

LANCIA: DELTA.

LAMBORGHINI: DIABLO, ESPADA, FRAU FAENA, MIURA, MURCIELAGO.

LEXUS: PREVIA.

LINCOLN: CONTINENTAL.

LOTUS: EXIGE.

MAZDA: FAMILIA.

MERCEDES BENZ: VITO MARCO POLO.

MITSUBISHIi: DIAMANTE, ECLIPSE, PAJERO ${ }^{11}$, SIGMA.

NISSAN: PRIMERA, PULSAR, SERENA, SILVIA, TINO.

OLDSMOBILE: AURORA.

OPEL: FILO, OMEGA, TIGRA.

PORSCHE: 911 CARRERA, 993 TURBO. 
RENAULT: LAGUNA.

ROLLS ROYCE \& BENTLEY: BENTLEY CONTINENTAL, BENTLEY TURBO.

SAAB: CONVERTIBLE.

SEAT: ALHAMBRA, CORDOBA, IBIZA, TOLEDO, CUPRA.

SUBARU: CASA BLANCA.

SUZUKI: ALTO WORKS, ESCUDO, LIANA, SOLIO.

TOYOTA: COROLLA, CORONA, PREMIO, SUPRA, TRUENO SPRINTER.

VOLKSWAGEN: GOLF, MICROBUS, POLO, TUAREG.

\section{La educación}

Hay un dicho oriental de que «Para cultivar un buen ginseng ${ }^{12}$ se requiere unos diez años, pero se necesitaría una centuria para obtener un ginseng silvestre». La educación como el ginseng requiere de un largo tiempo de cultivo y dedicación, por eso constituye la base de la sociedad moderna. En la época de la aldea global, abundan los términos de procedencias extranjeras en muchos libros y revistas, a la par de coincidir con los consumidores cada vez más jóvenes. En este sector, encontramos varios términos del español que guardan relación con la educación, así tenemos que los ordenadores Leo y la plaza de ofimática Nova ${ }^{13}$. El resto de las marcas relacionadas con «la educación» siguen, a saber:

a. Artículos de escritorio:

AURORA (fotocopiadora): MONO (goma de borrar), ZEBRA (bolígrafo).

b. Revistas: dedicadas a trajes para mujer: BELLA, BLANCA y COCO; dedicadas a revistas de trajes para damas y caballeros: COLOR; dedicadas a decoración moderna del hogar: CONDE, INTERIOR, y dedicadas a la colección de los coches: MOTOR.

c. Cabletelevisión: GALA CASA, ERA NEWS.

\section{El entretenimiento}

El cantante romántico latino «Julio» Iglesias, al igual que el tenor Plácido "Domingo», despiertan un especial interés en los estudiantes taiwaneses del español, ya que les son muy llamativos que algunos meses, algunos días de la semana se convierten en nombres de personas famosas. 
Seguidamente ofrecemos la subclasificación que hemos realizado con las siguientes marcas que llevan términos españoles o extraídos del español, a saber:

a. Agencia del viaje: COLA TOUR, FEDERAL TOUR, GLORIA TOUR.

b. Medios cinematográfico y de discos: LUNA SEA, CORAZÓN DE MELAO, CINEMAX, MIRAMAX, UNIVERSAL.

c. Show televisivo popular: USO! Japan!, VIVA VIVA V6.

En suma, no es dificil descubrir que de entre las numerosas marcas extranjeras, sobresalen muchos términos hispanizantes, sobre todo en las marcas de coches. Por lo tanto, aprender español no solamente puede ampliar la visión, sino también nos ayuda a entender el significado de las marcas de coches. (Por ejemplo: Trueno Sprinter de Toyota es la marca que combina español e inglés, Trueno en español es «el sonido de relámpago», Sprinter en inglés es «esprinter». Los hispanohablantes se familiarizan de esta forma con los vocablos españoles, pues son numerosas las marcas de coche que llevan nombres hispanizantes. Esto ayuda adicionalmente a mejorar el ambiente natural de aprendizaje a los estudiantes del idioma español.

\section{Conclusión}

Aunque la cultura española se está popularizando por todo el mundo, pero se precisa de una mayor difusión de su lengua en el Lejano Oriente, ya que nos damos cuenta con los ejemplos de términos hispanizantes, que la cultura española tiene una gran aceptación potencial en Taiwán. Creemos entonces que una de las formas más eficaz de promover la lengua es a través de la difusión cultural, cuando mejor se lo realiza mediante las actividades cotidianas, así se atrae natural y espontáneamente la atención de la gente, al mismo tiempo de conseguir el fin propagandístico. Cuando una marca en español o de connotaciones españolas logra satisfacer al consumidor local, seguramente va a crear un interés, y se produciría un efecto multiplicador positivo en su paulatina promoción entre las amistades y familiares.

Tras el análisis de los ejemplos citados, podemos concluir que las marcas comerciales representan también la imagen de un país. En el caso de España, especialmente tras su exitosa modernización industrial e incorporación a la Unión Europea a partir del año 1986, ha logrado dejar en el pasado la negativa imagen de pobreza y retraso social. El estatus in- 
ternacional de España ocupa un alto sitial reflejando una imagen de gran prestigio, de manera que cada día hay más y más compañías, incluyendo las taiwanesas, que consideran importar o denominar a sus productos con términos hispanizantes. Finalmente, la lengua y la cultura hispánica no solamente han coadyuvado a una mayor presencia de productos hispánicos que representan de una u otra manera a España, sino que han conseguido al mismo tiempo, difundir la lengua y la cultura española a la sociedad taiwanesa.

Según lo mencionado, no es dificil descubrir términos hispanizantes en los numerosos productos ofrecidos en el mercado de Taiwán. Un buen ambiente en sí facilita un buen aprendizaje, y mucha gente aprende el español sin darse de cuenta. Si podemos hacer que los consumidores se encariñan con los productos que llevan denominaciones hispanizantes, igualmente podríamos hacer que les gusten el español mediante tales productos, y así los consumidores se van aprendiendo el español con placer.

\section{Bibliografia}

1. BASSAT, L.(1993): El libro rojo de la publicidad (Ideas que mueven montañas). Barcelona, Folio.

2. BoraO, J. E. (2002): Spaniards in Taiwan. 2 vols, Taipei, SMC Publishing Inc.

3. Chang, M. T.(1996): «Estudio sobre la "progresión temática" y la aplicación de figuras retóricas en publicidad», Revista de Filología Hispánica (RILCE) 12-1, 26-37.

4. Chang, M. T. (1998): "El análisis comparativo entre el Oriente y el Occidente sobre el aprendizaje del idioma: el valor de la equivalencia en la traducción, intercambio trans-cultural y didáctica de lenguas extranjeras" (Colección de ponencias presentadas en la tercera conferencia sobre didáctica de la lengua española a los dos lados del estrecho de Taiwán): Tianjin, «Baihua Literature and Art Publishing House» (Tianjin Foreign Studies University,China), 402-417.

5. ChANG, M. T. (2001): "Aprender el español con placer: desde el punto de vista de la técnica de traducción", (Colección de ponencias presentadas en la quinta conferencia sobre didácticas de la lengua española a los dos lados del estrecho de Taiwán): Xi-An, El Colegio de Lenguas Extranjeras de Xi-An, 104-122.

6. ChANG, M. T. (2002a): "Aprender el español con placer: desde el punto de vista de la publicidad comercial), (Colección de ponencias presentadas en la sexta conferencia sobre didácticas de la lengua española a los dos lados del estrecho de Taiwán): Tamsui, Universidad de Tamkang, 591-606. «http://dctsp.ec.tku.edu.tw/QuickPlace/090621qp/ Main.nsf/h_Library/82794D7B24A5380948256F55000FCC48/?OpenDocument»

7. Chang, M. T. (2002b): "Aprender el español con placer: ejemplo de marcas de coches", Literatura Mundial 6, 8-29. «http://dctsp.ec.tku.edu.tw/QuickPlace/090621qp/ Main.nsf/h_Library/18BF37D4E1278D3748256F6300309AA0/?OpenDocument»

8. CHANG, M. T. (2002c): «Aprender el español con placer: desde el punto de vista del consumo de la cultura actual y aprendizaje de lengua extranjera», Primera Conferencia sobre las Lenguas y los Currículos de Cultura, Universidad Taipei, 123-140. 
«http://dctsp.ec.tku.edu.tw/QuickPlace/090621qp/Main.nsf/h_Library/C17D99F75AF 3065548256F720007F31B/?OpenDocument».

9. CHANG, M. T. (2003): "Análisis de unas marcas de coche que llevan términos hispanizantes", Encuentros en Catay 2003, 317-323, Taipei, Fu-Jen CatholicUniversity. «http://dctsp.ec.tku.edu.tw/QuickPlace/090621qp/Main.nsf/h_Library/F0BC175E5A6 F269448256F930048EAEC/?OpenDocument»

10. Chang, M. T. (2005): "La presencia del español en la vida diaria en Taiwán", Círculo de lingüistca aplicada a la comunicación, Número 21, Febrero 2005, ISSN 1576. 4737«http://www.ucm.es/info/circulo/no21/Taiwán.htm», 2005.

11. JHALly, S. (1987): The codes of Advertising. Taipei, "Yuan-Liou».

12. PEÑA PÉREZ, G. (1999): «El valor persuasivo del eslogan publicitario», Círculo de lingüística aplicada a la comunicación 6, ISSN 1576-4737. «http://www.ucm.es/info/ circulo/no6/pena.htm" y Publicado en La lengua y los medios de comunicación, Madrid, Servicio de Publicaciones de la Universidad Complutense de Madrid, 2001, 143-154.

13. Romera, César San Nicolás (2002): "La nominación publicitaria. Procesos semionomasiológicos para la creación estratégica de nombres de marcas", «http://www.um.es/ tonosdigital/znum3/estudios/NominacionPublicitaria.htm»

14. WANG, W.H. (2002): Los cuatro elementos para crear un buen logo: nombre, visión, música y eslogan, Revista Tecvantage, edición digital.

\section{Apéndice (Algunas marcas conocidas en Taiwán)}

\section{Gastronomía:}

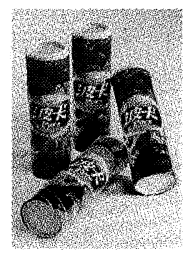

Poca (少) 波卡洋芋片
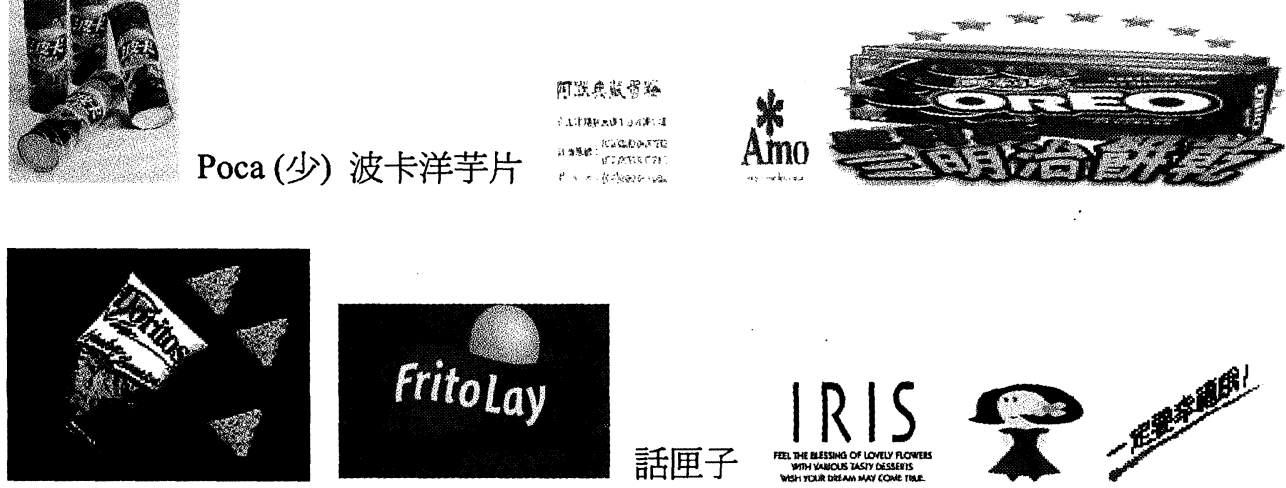

\section{Vestimenta}

http://members.tripod.com/hibiscusstar/arena200/index-1.htm

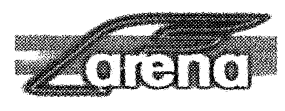

(泳裝) 

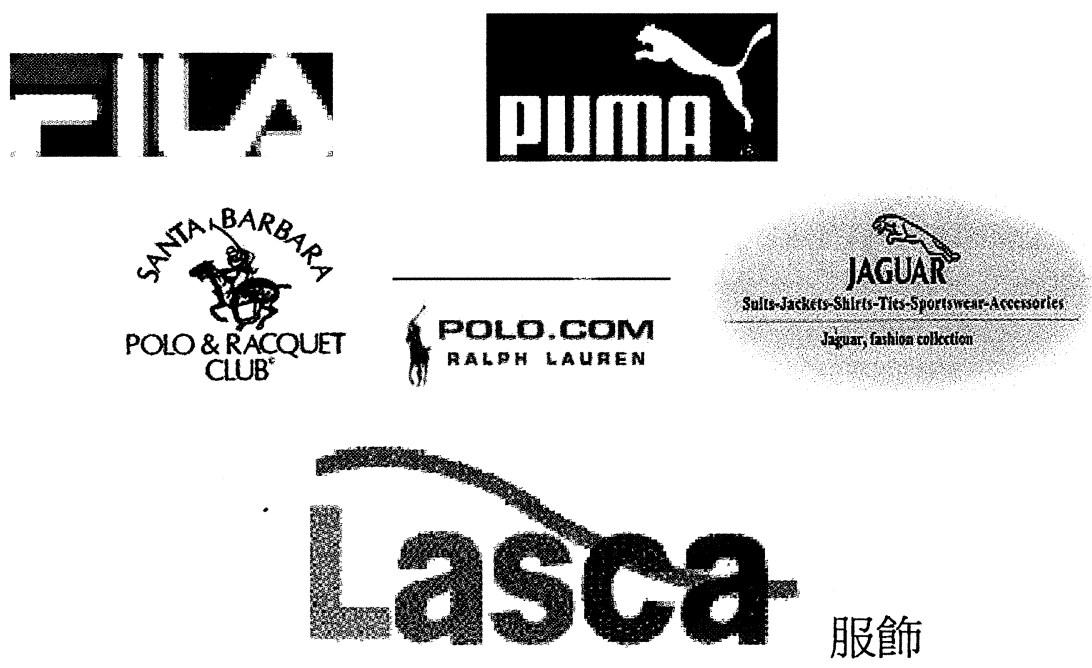

服飾

\section{Vivienda}

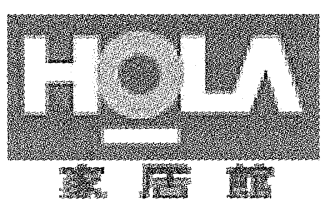

\section{Transporte}
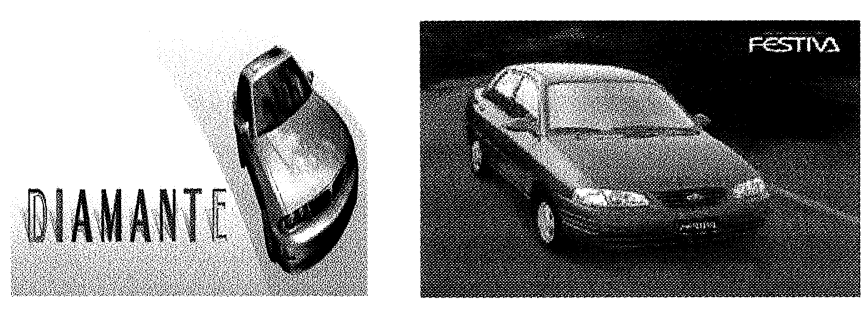

Nompungucna

\begin{tabular}{|c|c|}
\hline 58 & - \\
\hline A.that & 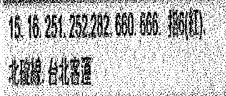 \\
\hline buteth & 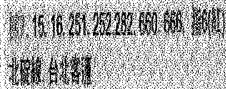 \\
\hline
\end{tabular}

\section{Educación}

\section{LOOO BIRD S-7

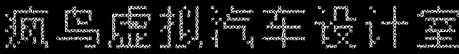

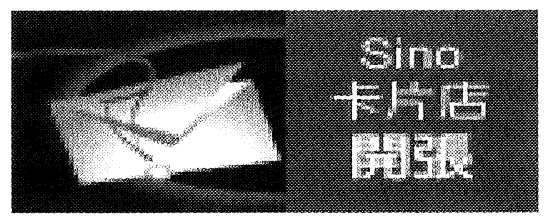




\section{Mauh-Tsun Chang}

\section{Entretenimiento}
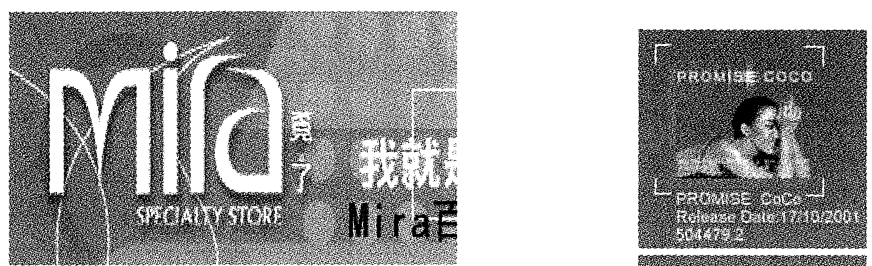

\section{中鞎国閏放系統搏合

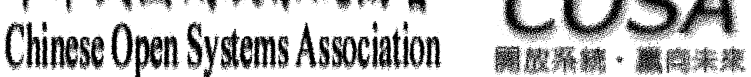

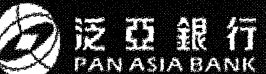

\section{ALMA}

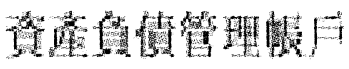

http://www.hibank.comtw/ALMA/1.html

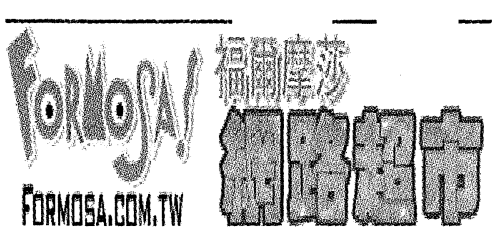

http://www.formosa.comtw/supermarkert/view2.asp?type2_no=4\&Page= 9\&type1_no=4

\section{Notas}

* El autor agradece el respaldo financiero brindado por el Consejo Nacional de Ciencias, de la República de China en Taiwán, a través del proyecto NSC91-2411-H-032-011, NSC 92-2411-H-032-005 y NSC 93-2411-H-032-016.

1 Comp. Chang (2002a, 2002b, 2002c, 2003, 2005). Dentro de las marcas citadas, aunque no todas son igualmente conocidas por los consumindores, se podría promocionar su significado hispanizante. Esta tarea bien puede desempeñarla los profesores de español. 


\section{España y el español en Taiwán}

${ }^{2}$ Guam, una isla norteamericana en el Pacífico Asiático, que fue cedida tras la guerra de norteamericano-española, que tuvo lugar en el año 1898. «http://dollar.com.gu/His tory.htm»

3 Comp. Borao (2002).

4 «http://www.ttv.com.tw/AIR_ART/PROGRAM90/200104/H20010422028.htm».

5 El profesor Borao tiene una webpágina dedicada a este tema «http://ccsun57.cc.ntu. edu.tw/ borao/Cultura/Fortalezas/homepage.htm». mayor detalle se puede consultar en Borao (2002).

6 Su webpágina oficial en español:«http://www.lladro.com/lladro/def/sp/index1.html».

7 En el presente artículo, hemos considerado también como términos hispanizantes a aquéllas marcas encontradas sin el tilde.

8 Comp. Chang (2002b).

9 Aquí la palabra «metro» alude a lo metropolitano; y la voz anglosajona «star» se re fiere a estrella.

10 Dentro de las marcas de motocicleta solo encontramos a la marca «Vino» de YAMAHA que guarda relación con el español.

11 Cuidado en no confundir pajero con pájaro. El primero es la marca hispanizante de un coche de Mitsubishi, y el segundo no.

12 Para mayor detalle acerca del ginseng, véase la siguiente dirección:«perso.wanadoo.es/elperic/E/eleuterococcus_senticosum/eleuterococcus_senticosum.htm».

13 El significado español es «la nueva estrella». 